\title{
Assisted laser ablation: silver/gold nanostructures coated with silica
}

\author{
J. R. González-Castillo ${ }^{1}$ (D) Eugenio Rodríguez-González ${ }^{1} \cdot$ Ernesto Jiménez-Villar $^{2}$ • \\ Carlos Lenz Cesar ${ }^{3} \cdot$ Jacob Antonio Andrade-Arvizu $^{4}$
}

Received: 20 July 2017/Accepted: 14 September 2017/Published online: 21 September 2017

(c) The Author(s) 2017. This article is an open access publication

\begin{abstract}
The synthesis processes of metallic nanoparticles have seen a growing interest in recent years, mainly by the potential applications of the phenomenon of localized surface plasmon resonance associated with metallic nanoparticles. This paper shows a fast method to synthesize silver, gold and silver/gold alloy nanoparticles coated with a porous silica shell by the assisted laser ablation method in three steps. The method involves a redox chemical reaction where the reducing agent is supplied in nanometric form by laser ablation. In the first step, a silicon target immersed in water is ablated for several minutes. Later, $\mathrm{AgNO}_{3}$ and $\mathrm{HAuCl}_{4}$ aliquots are added to the solution. The redox reaction between the silver and gold ions and products resulting from ablation process can produce silver, gold or silver/gold alloy nanoparticles coated with a porous silica shell. The influence of the laser pulse energy, ablation time, $\mathrm{Ag}^{+}$and $\mathrm{Au}^{3+}$ concentration, as well as the $\mathrm{Ag}^{+} / \mathrm{Au}^{3+}$ ratio, on optical and structural properties of the nanostructures was investigated. This work represents a step forward in the study of reaction mechanisms that take place during the synthesis of nanoscale materials by the assisted laser ablation technique.
\end{abstract}

J. R. González-Castillo

g_c_j_r@hotmail.com

1 Instituto Politécnico Nacional, CICATA UA, 89600 Altamira, Mexico

2 Universidade Federal de Pernambuco, DQF, Recife 50670-901, Brazil

3 Universidade Estadual de Campinas, IFGW-DEQ, Campinas 13083-859, Brazil

4 Escuela Superior de Física y Matemáticas-Instituto Politécnico Nacional (ESFM-IPN), 07738 Mexico City, Mexico
Keywords Silver/gold nanostructures - Assisted laser ablation $\cdot$ Metallic nanoparticles $\cdot$ Core-shell nanoparticles

\section{Introduction}

The study of nanometric structures of different materials is constantly evolving and every day there are a greater number of applications in which we find these nanomaterials (Zhang et al. 2005; Rodriguez et al. 2008; Kellermann et al. 2010; Fuertes et al. 2011; Bankura et al. 2012; Garcia 2012; Prabhu and Poulose 2012; Liao et al. 2013; Liu et al. 2014; Al-Azawi et al. 2016; Zhang et al. 2017). There are different pathways for synthesizing nanoparticles (NPs); however, it is a challenge for all of them to improve the control of physical properties of the nanostructures, since their behavior will largely depend on their characteristics (Fojtik et al. 1993; Jiménez et al. 2004; Pyatenko et al. 2004; Popovici et al. 2006; Pyatenko et al. 2007; Jiménez et al. 2008; Cobley et al. 2009; Jiménez et al. 2010; González-Castillo et al. 2015; Ermakov et al. 2017). In 2008 , Jiménez et al. demonstrated a novel hybrid physicalchemical method based on a chemical reaction assisted by laser ablation (Jiménez et al. 2008). This is a fast and simple method to synthesize metal-core/dielectric-shell NPs in one step and in an aqueous medium. This method, assisted laser ablation (ALA), is basically a chemical synthesis (redox) where one of the reactants (silicon) is supplied in nanometer dimensions by laser ablation (Jiménez et al. 2010). The laser ablation method is a powerful technique for producing nanostructured materials in different environments (Fojtik et al. 1993; Jiménez et al. 2004; Pyatenko et al. 2004; Popovici et al. 2006; Ermakov et al. 2017). Recently, González-Castillo et al. reported the

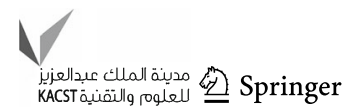


synthesis of silver (Ag) NPs by ALA in two steps (González-Castillo et al. 2015). In the first step, the laser ablation process produces silicon NPs that are subsequently oxidized in the aqueous solution, yielding silica NPs. In the second step, the silver salt $\left(\mathrm{AgNO}_{3}\right)$ was added. In a subsequent work, (Ermakov et al. 2017) $\mathrm{SiO}_{2} \mathrm{H}_{2}$ isomers on the silica NP surface (McCarthy and Gauss 2016), produced during the vigorous oxidation of silicon NPs (laser ablation), were proposed as possible reducing agents of the silver ions. The silica coatings provide inertness and high dispersibility, which has enabled their use in numerous applications (Rodriguez et al. 2005; Abderrafi et al. 2012; Jimenez-Villar et al. 2013, 2014, 2016, 2017). In this paper, we report the influence of the laser radiation parameters on the synthesis of silver, gold and $\mathrm{Ag} / \mathrm{Au}$ alloy NPs with a silica coating. Recently, researchers reported the synthesis and study of Ag/Au alloy NPs (Qingbo et al. 2007; Kumar and Yadav 2009; Csapó et al. 2012; SánchezMuñoz et al. 2012; Olea-Mejía et al. 2015; Shiomi et al. 2015; Nasrabadi et al. 2016); however, there is a lack of information regarding the implications of making a change in the conditions under which these materials are synthesized. In this sense, a detailed study of the synthesis parameters would be a breakthrough for achieving control on the physical properties of $\mathrm{Ag} / \mathrm{Au}$ nanostructures.

\section{Experimental}

The experimental setup for manufacturing core-shell metal/silica NPs is shown in Fig. 1. Samples containing $\mathrm{Ag} / \mathrm{Au} \mathrm{NPs}$ coated with silica (Ag/Au@Silica) were synthesized combining both a physical and a chemical (redox) route (assisted laser ablation). As a first step, nanometric silicon NPs, which are vigorously oxidized in direct contact with water, are produced by laser ablation of a $4 \mathrm{~N}$ pure silicon target situated at the bottom of a beaker containing $20 \mathrm{~mL}$ of Milli-Q water. The silicon target was ablated using the fundamental harmonic $(\lambda=1064 \mathrm{~nm})$ of a $Q$-switched Nd:YAG laser (Quantel Q-Smart 450), which delivers 5-ns laser pulses at $20 \mathrm{~Hz}$. The nanometric and subnanometric silica NPs resulting from the first step of laser ablation are dispersed in the aqueous solution. In the second step, an ionic concentration of silver salt $\mathrm{AgNO}_{3}$ was added to the aqueous solution resulting from the laser ablation process, and consequently Ag NPs were formed. Just after adding the silver salt, an aliquot of gold salt $\left(\mathrm{HAuCl}_{4}\right)$ was added to the solution (third step), finally leading to the formation of $\mathrm{Ag} / \mathrm{Au}$ or $\mathrm{Au}$ NPs coated with a porous silica shell (Ag/Au@Silica).

To study the optical and structural properties of $\mathrm{Ag} /$ Au@Silica NPs as a function of growth parameters, samples were prepared by modifying the time used for the target ablation from 1 to $20 \mathrm{~min}$, the concentration of the metal salts $\mathrm{AgNO}_{3}$ and $\mathrm{HAuCl}_{4}$ from $0.05 \times 10^{-3}$ to $0.35 \times 10^{-3} \mathrm{M}$ and the $\mathrm{Ag} / \mathrm{Au}$ percentage ratio (100/0, $95 / 5,90 / 10,85 / 15,80 / 20$ and 0/100), respectively. For sample synthesis, discrete values of laser pulse energy 5 , $10,15,30$ and $50 \mathrm{~mJ}$ were used which yields a fluence $\left(\rho_{E}\right)$ at the target surface of $2.55,5.10,7.65,15.30$ and $25.50 \mathrm{~J} /$ $\mathrm{cm}^{2}$, respectively.

The synthesized samples were then characterized by high-resolution transmission electron microscopy (HRTEM) on a JEOL JEM3010 $300 \mathrm{kV}$ with a thermionic electron gun. The structural properties were studied by X-ray diffraction (XRD) using a Bruker D8 Advance diffractometer XRD in powder configuration sweeping $2 \theta$ from 20 to $80^{\circ}$. The samples for the XRD study were prepared by drop casting the $\mathrm{Ag}, \mathrm{Au}$ and $\mathrm{Ag} / \mathrm{Au}$ NP suspensions on a hot glass plate $\left(100{ }^{\circ} \mathrm{C}\right)$, to evaporate the $\mathrm{H}_{2} \mathrm{O}$ content and to form a film thick enough to be measured by XRD. Absorption spectra were obtained on a Cary 5000 UV-Vis-NIR spectrophotometer.
Fig. 1 Schematic diagram of the experimental setup for nanoparticles production
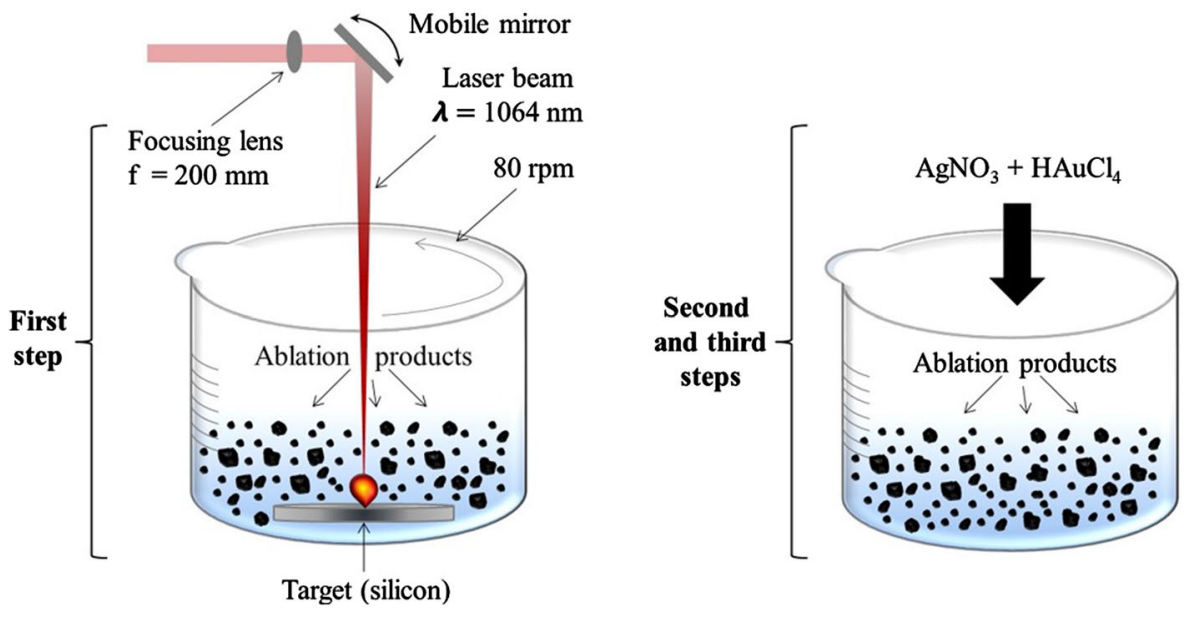


\section{Results and discussion}

\section{Influence of the alloy percent}

To study the synthesis process of Ag/Au@Silica NPs, the $\mathrm{Ag}^{+} / \mathrm{Au}^{3+}$ percentage ratio added to solution after ablation is varied from $95 / 5$ to $80 / 20$, keeping constant the total concentration of $\mathrm{Ag}$ plus $\mathrm{Au}$ salts at $\left[0.35 \times 10^{-3}\right]$. Figure 2a shows the absorption spectra corresponding to the colloidal suspensions synthesized with a different $\mathrm{Ag}^{+}$/ $\mathrm{Au}^{3+}$ percentage ratio of 100/0, 95/5, 90/10, 85/15, 80/20 and $0 / 100$.

To better understand the behavior of the localized surface plasmon resonance (LSPR), Fig. $2 b$ shows the dependence of basic features of the LSPR absorption band, namely its center wavelength (CWL) and the maximum absorbance (LSPR intensity) on the $\mathrm{Ag}^{+} / \mathrm{Au}^{3+}$ percentage ratio.

Results show that the CWLs for pure silver and gold colloids were located at 419 and $560 \mathrm{~nm}$, respectively. At low $\mathrm{Au}^{3+}$ percentage $(\leq 10 \%)$, only one LSPR absorption band can be observed. However, at $\mathrm{Ag}^{+} / \mathrm{Au}^{3+}$ of $85 / 15$ and 80/20, the LSPR reveals the presence of two absorption bands. The LSPR intensity decreases for the band of shorter wavelength as the percentage of silver ions is reduced. An increase in LSPR intensity is observed for the second band, located at longer wavelengths, as the $\mathrm{Au}^{3+}$ proportion is increased. Additionally, a red shift from 410 to $430 \mathrm{~nm}$ is observed for the shorter wavelength band as the $\mathrm{Au}^{3+}$ proportion is increased. This latter is in agreement with the formation of core-shell nanoparticles (Sánchez-Muñoz et al. 2012). Notice that the reduction potential of $\mathrm{Au}^{3+}$ is higher than that of $\mathrm{Ag}^{+}$. Consequently, silver NPs formed after $\mathrm{Ag}^{+}$addition must be partially

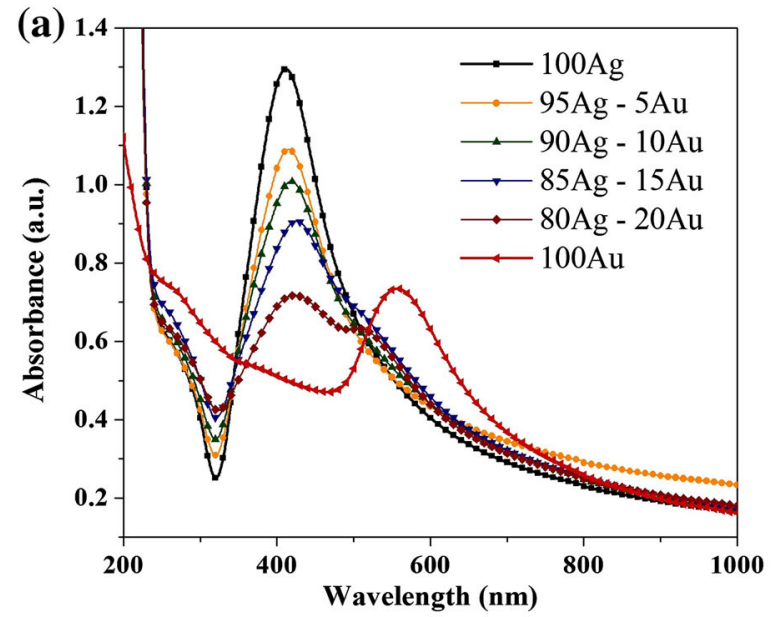

Fig. 2 a Absorption spectra of Ag/Au@Silica alloy NP suspensions synthesized with the following parameters: $E_{\text {pulse }}=50 \mathrm{~mJ}$, $t=20 \mathrm{~min}, f=20 \mathrm{~Hz}, \lambda=1064 \mathrm{~nm},\left[0.35 \times 10^{-3}\right]$ and different oxidized by the $\mathrm{Au}^{3+}$ ions in accordance with the substitution reaction (Qingbo et al. 2007; Sánchez-Muñoz et al. 2012):

$$
3 \mathrm{Ag}_{(\mathrm{s})}+\mathrm{HAuCl}_{4(\mathrm{aq})} \rightarrow \mathrm{Au}_{(s)}+3 \mathrm{Ag}^{+}+\mathrm{H}^{+}+4 \mathrm{Cl}_{(\mathrm{aq})}^{-} \text {. }
$$

According to the stoichiometry of previous reaction, three $\mathrm{Ag}$ atoms can be substituted by each $\mathrm{Au}^{3+}$ ion. Consequently, the appearance of a second absorption band, associated with gold LSPR, is expected along with a decrease of the NP size.

It is worth noticing that in this experiment both the pulse energy and ablation time were kept constant, consequently the amount of nanometric silicon extracted from the target must be approximately the same. By decreasing the $\left[\mathrm{Ag}^{+}\right]$ percentage added to the aqueous solution in the second stage of synthesis process, a decrease in the metallic silver is expected. Further addition of the Au salt leads to a higher amount of gold atoms in the Ag/Au NPs. The red shift of silver LSPR (from $\sim 410$ to $430 \mathrm{~nm}$ ) could be associated with the high dielectric permittivity of the gold shell.

\section{Influence of $\mathrm{AgNO}_{3}$ and $\mathrm{HAuCl}_{4}$}

To study the influence of the concentration of the metallic salts on the Ag/Au@Silica synthesis process, samples with $\left[\mathrm{Ag}^{+}\right]$plus $\left[\mathrm{Au}^{3+}\right]$ from 0.05 to $0.35 \mathrm{mM}$ were prepared. The $\mathrm{Ag}^{+} / \mathrm{Au}^{3+}$ ratio was equal to unity $\left(\left[\mathrm{Ag}^{+}\right] /\right.$ $\left[\mathrm{Au}^{3+}\right]=1$ ) for all these samples. The absorption spectra are shown in Fig. 3a. At low $\left[\mathrm{Ag}^{+}\right]+\left[\mathrm{Au}^{3+}\right](0.05 \mathrm{mM})$, two absorption bands are observed. This could be a consequence of the low amount of silver NPs formed in the second step. Consequently, the reducing agent of $\mathrm{Au}^{3+}$ ions could be preferably the $\mathrm{SiO}_{2} \mathrm{H}_{2}$ isomers, instead of the

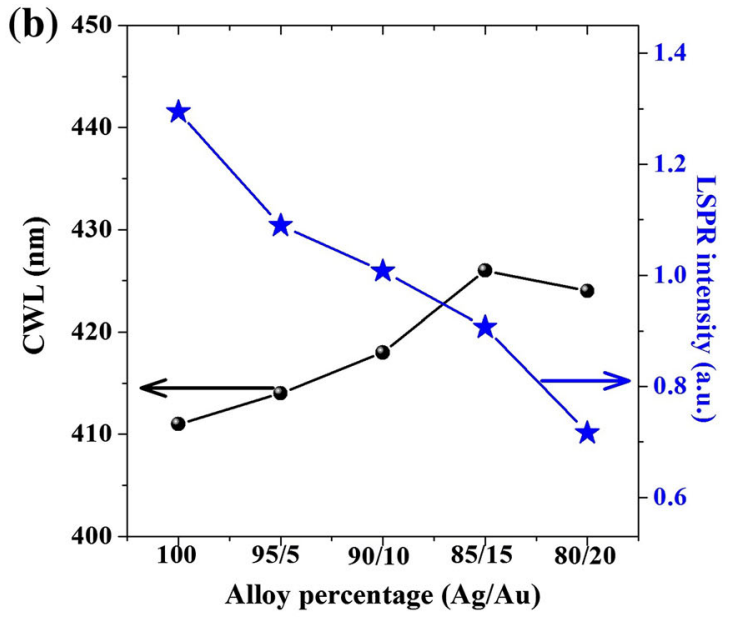

alloy percentages. b Dependence of CWL and LSPR intensity on the $\mathrm{Ag}^{+} / \mathrm{Au}^{3+}$ percentage for the silver LSPR 


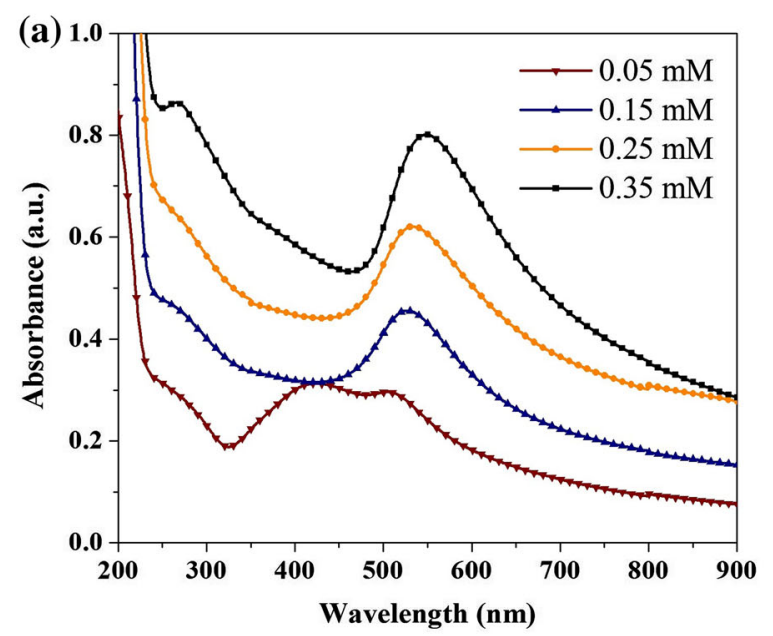

Fig. 3 a Absorption spectra of the Ag/Au@Silica NP suspensions synthesized with the following parameters $E_{\text {pulse }}=50 \mathrm{~mJ}$, $t=20 \mathrm{~min}, f=20 \mathrm{~Hz}, \lambda=1064 \mathrm{~nm}$ and different $\left[\mathrm{AgNO}_{3}\right.$ plus

Ag NPs, due to low Ag NPs as compared to $\left[\mathrm{SiO}_{2} \mathrm{H}_{2}\right]$. Thereby, the colloidal suspension would be composed mainly by silver and gold NPs separately. Figure $3 \mathrm{~b}$ presents the dependence of the LSPR parameters on $\left[\mathrm{AgNO}_{3}\right]$ and $\left[\mathrm{HAuCl}_{4}\right]$, revealing an increase in the LSPR intensity as the metallic salt concentrations are increased. This suggests that having a greater availability of silver and gold ions makes it possible to produce more NPs.

At higher concentrations of the metallic salt, only one absorption band is observed. This must be because the silver NPs are completely oxidized by $\mathrm{Au}^{3+}$ ions [substitution reaction (1)], which leads to gold NPs. Notice that the $\mathrm{Ag}^{+}$and $\mathrm{Au}^{3+}$ proportion is $50 \%$. The CWL of the gold LSPR red shifts from $\sim 520$ to $550 \mathrm{~nm}$ when metallic salt concentration $\left(\left[\mathrm{Ag}^{+}\right],\left[\mathrm{Au}^{3+}\right]\right)$ is increased. This could be because of the increase of NP size and/or the presence of $\mathrm{AgCl}$ precipitate on the NP surface. Notice that $\mathrm{AgCl}$ is a product of the substitution reaction (1).

\section{Influence of the laser energy}

To study the influence of the laser energy, samples were prepared by varying the laser pulse energy from 5 to $50 \mathrm{~mJ}$. The total salt concentration added $\left(\left[\mathrm{Ag}^{+}\right]\right.$plus $\left.\left[\mathrm{Au}^{3+}\right]\right)$ was $\left[0.35 \times 10^{-3}\right]$ and the $\mathrm{Ag} / \mathrm{Au}$ atomic ratio was $1: 1$. The ablation time was kept constant for all samples at $20 \mathrm{~min}$ (4000 laser pulses). Figure $4 \mathrm{a}$ and $\mathrm{b}$ shows the absorption spectra and the dependence of the LSPR parameters as a function of the laser pulse energy. The absorption spectra exhibit an absorption band around $550 \mathrm{~nm}$, which is a feature of gold NPs. Notice that each $\mathrm{Au}^{3+}$ ion must substitute $3 \mathrm{Ag}$ atoms, so the silver NPs formed in the second step must be completely oxidized after the addition of the gold salt $\left(\left[\mathrm{Ag}^{+}\right] /\left[\mathrm{Au}^{3+}\right]=1\right)$. An increase of the LSPR

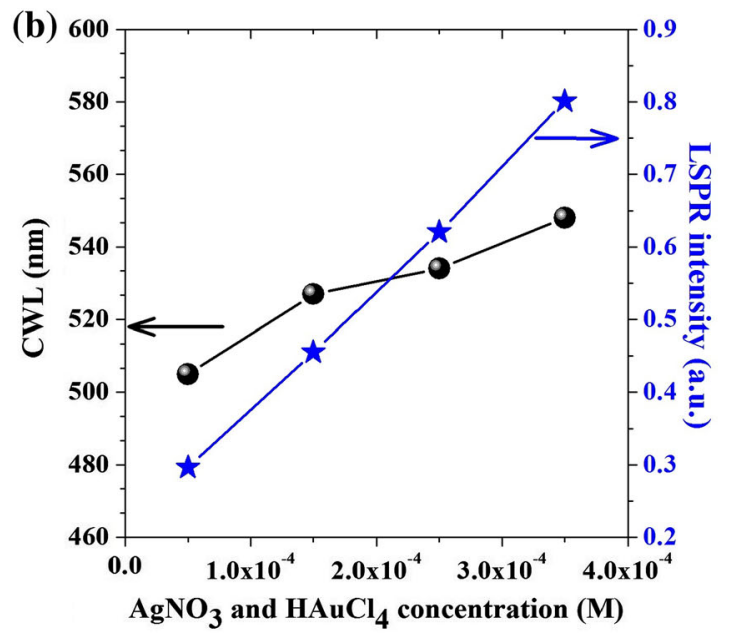

$\mathrm{HAuCl}_{4}$ ]. b LSPR parameters: CWL and intensity vs. $\left[\mathrm{AgNO}_{3}\right.$ plus $\left.\mathrm{HAuCl}_{4}\right]$. The $\mathrm{Ag}^{+} / \mathrm{Au}^{3+}$ atomic ratio was $1: 1$ for all these samples

intensity is observed as laser pulse energy is increased. An increase of the pulse energy must increase the amount of nanometric silicon extracted from target. Consequently, the quantity of $\mathrm{SiO}_{2} \mathrm{H}_{2}$ isomers (reducing agent), formed on the silica NP surface during the vigorous oxidation of silicon NPs, must also increase. Therefore, an increase of the amount of reduction center is expected, which must lead to a decrease of the silver NP size and an increase in the silver NPs. Once the Au salt is added, Au NPs must be formed by the substitution reaction (1). Notice that for $\mathrm{Ag}^{+} /$ $\mathrm{Au}^{3+}=1$, the silver NPs, formed in the second step, must be oxidized completely leading to NPs made up of $100 \%$ $\mathrm{Au}$. The Au NPs have identical crystal structure to Ag NPs, since the atomic radii of $\mathrm{Ag}(1.65 \AA)$ and $\mathrm{Au}(1.74 \AA)$ atoms are similar. Consequently, the diminution of the $\mathrm{Ag}$ NP size also implies a reduction of the Au NP size, which is consistent with the CWL blue shift $(562-549 \mathrm{~nm})$ observed as the laser pulse energy is increased (Fig. 4b). For energies $\geq 50 \mathrm{~mJ}$, the LSPR intensity exhibits a trend to saturate. We note an increase of the background intensity in the absorption spectra as pulse energy is increased. This latter must be a consequence of an increase of the amount of silicon with big size (splashing) extracted during the ablation process, which gives rise to an increase of light scattering.

\section{Influence of the ablation time}

To study the influence of the ablation time, samples were prepared using $\lambda=1064 \mathrm{~nm}, \mathrm{f}=20 \mathrm{~Hz}$, and $5 \mathrm{~mJ}$ laser pulse energy. The total concentration of metallic salts added to all samples is $\left[0.35 \times 10^{-3}\right]\left(\left[\mathrm{Ag}^{+}\right] /\left[\mathrm{Au}^{3+}\right]=1\right)$. Figure 5a shows the absorption spectra for colloidal suspensions synthesized with different times of laser 

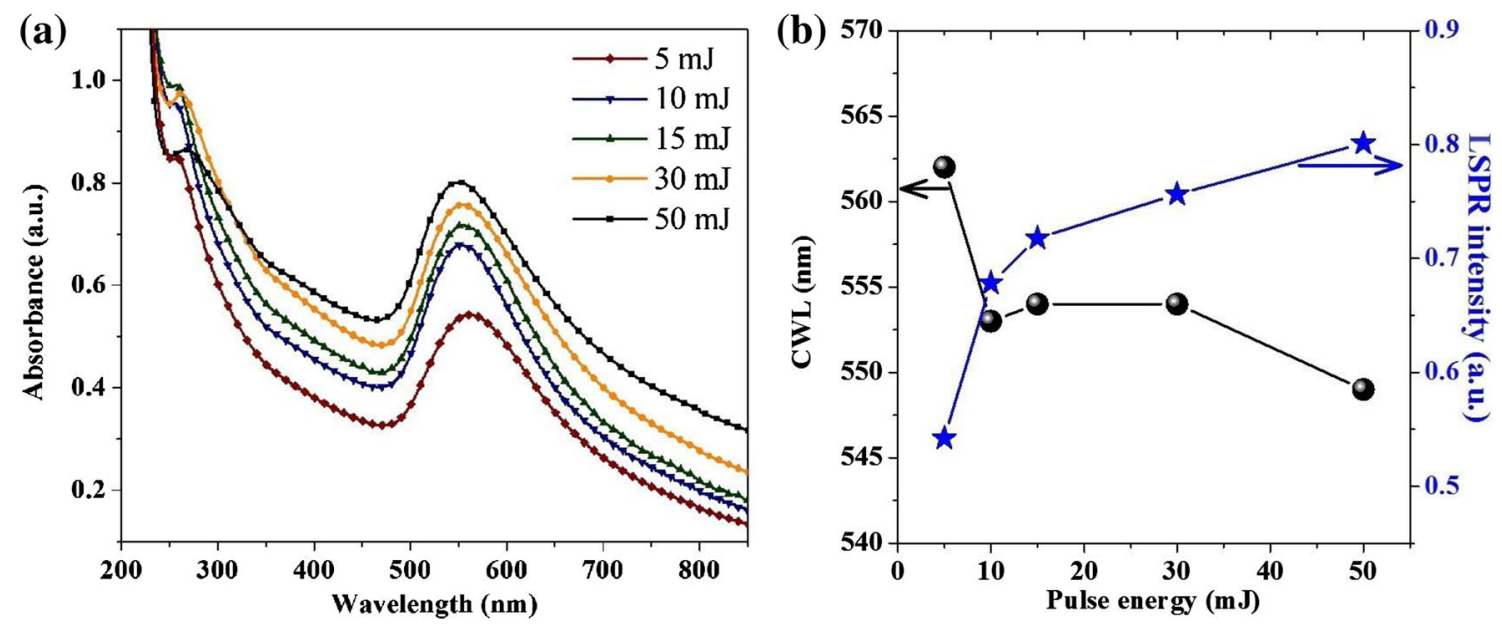

Fig. 4 a Absorption spectra of colloidal suspensions synthesized with $\lambda=1064 \mathrm{~nm}, f=20 \mathrm{~Hz}, t=20 \mathrm{~min},\left[0.35 \times 10^{-3}\right]$ of $\mathrm{AgNO}_{3}$ plus $\mathrm{HAuCl}_{4}$, and laser pulse energy between 5 and $50 \mathrm{~mJ}$. b CWL and LSPR intensity vs. laser pulse energy

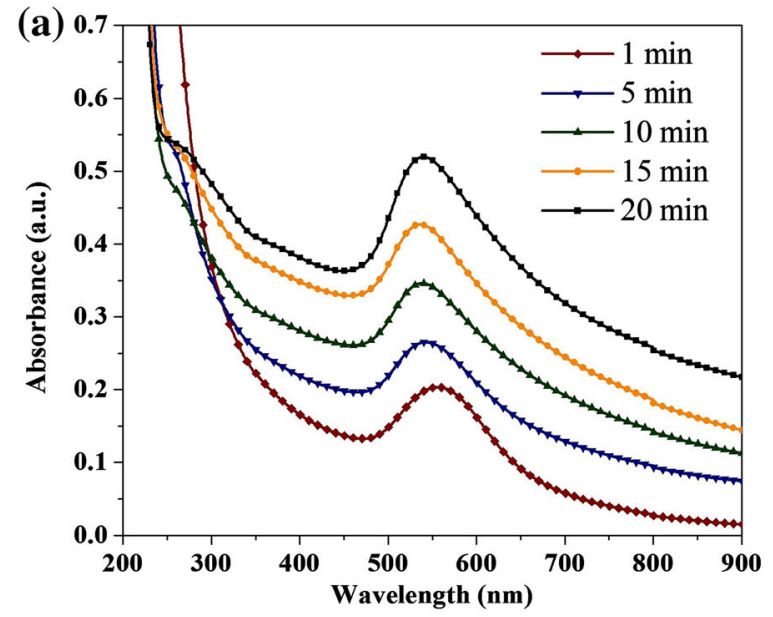

Fig. 5 a Absorption spectra of colloidal suspensions (Ag/Au@Silica alloy NPs) synthesized using a laser pulse energy of $5 \mathrm{~mJ}$, $\lambda=1064 \mathrm{~nm}, f=20 \mathrm{~Hz},\left[0.35 \times 10^{-3}\right]$ of $\mathrm{AgNO}_{3}$ plus $\mathrm{HAuCl}_{4}$

irradiation. Figure $5 \mathrm{~b}$ shows the dependence of absorption spectrum and LSPR parameters on the synthesis time. The presence of only one absorption band around $550 \mathrm{~nm}$ in the spectra confirms the formation of Au NPs. As the ablation time increases from 1 to $20 \mathrm{~min}$, an increase of the LSPR intensity is observed, which is due to an increase in NPs. This latter must be provoked by an increase of nanometric silicon, produced during laser ablation (first stage), which represents an increase of $\left[\mathrm{SiO}_{2} \mathrm{H}_{2}\right]$ isomers (reducing agent) that in turn induces an increase of NPs synthesized after adding the metallic salts. An increase of the background intensity of the absorption spectra is also observed as ablation time is increased. This latter must be a consequence of the increase of the amount of material extracted (big silicon particles) during the ablation process, which increases the scattering of light. Figure $5 \mathrm{~b}$ reveals that the

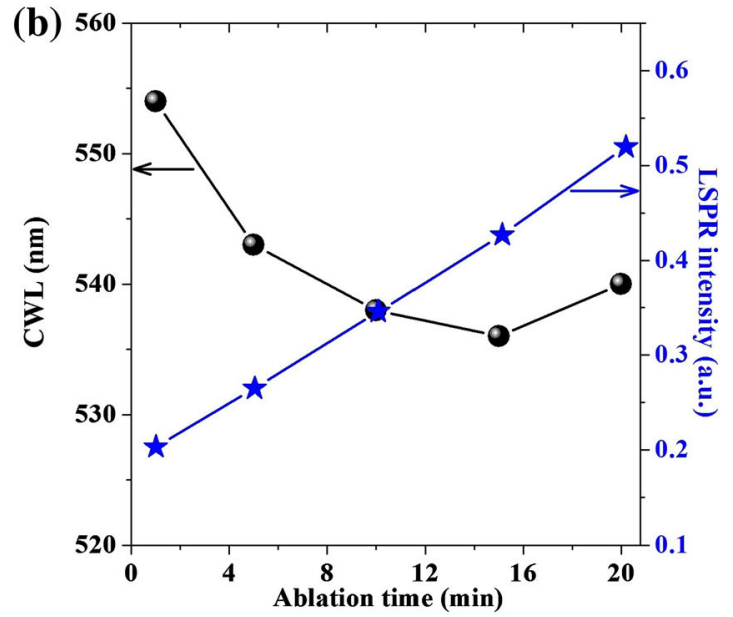

and different ablation times. b Plasmon parameters: CWL and LSPR intensity vs. ablation time

CWL located around $550 \mathrm{~nm}$ blue shifts from 554 to $536 \mathrm{~nm}$ as the ablation time increases from 1 to $20 \mathrm{~min}$. This blue shift can be because of a reduction in the NP size and/or the increase of nanometric silica in suspension. Notice that an increase of the nanometric silica in suspension must cause a decrease in the $\mathrm{AgCl}$ precipitate on the formed Au@Silica NPs, since the $\mathrm{AgCl}$ precipitate must be distributed on high silica area.

Figure 6 shows the XRD spectrum of sample synthesized using the synthesis parameters: $E_{\text {pulse }}=50 \mathrm{~mJ}$, $\lambda=1064 \mathrm{~nm}, f=20 \mathrm{~Hz}, t=20 \mathrm{~min}$ and $\left[0.25 \times 10^{-3}\right]$ of $\mathrm{AgNO}_{3}$ plus $\mathrm{HAuCl}_{4}$. The absorbance of this sample is presented in Fig. 3a. The diffractogram shows peaks located at $2 \theta=38.4^{\circ}, 44.5^{\circ}, 64.8^{\circ}$ and $77.6^{\circ}$, corresponding to reflections of the gold crystalline planes (111), (200), (220) and (311), respectively. 
(a)

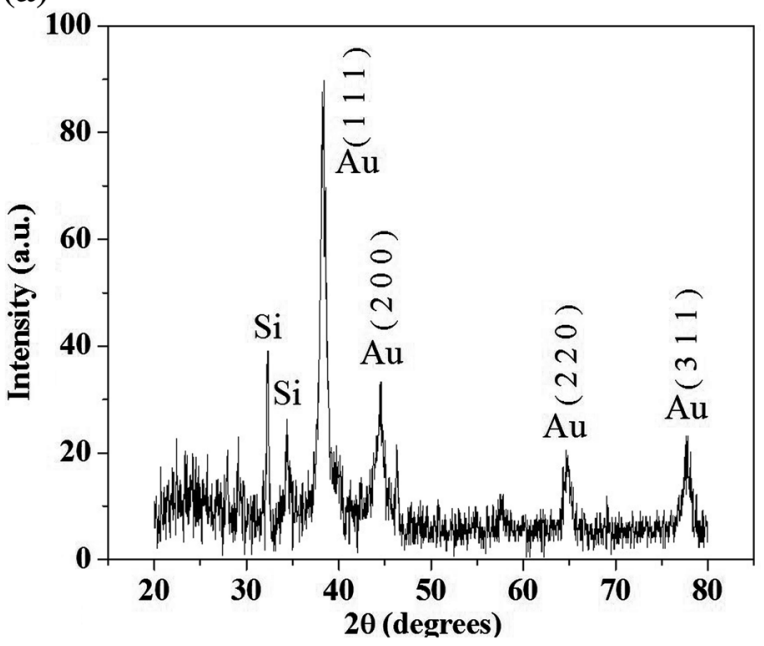

(b)

\begin{tabular}{|c|c|c|}
\hline \multicolumn{3}{|c|}{ Scherrer } \\
\hline $\begin{array}{c}\text { Diffraction } \\
\text { peaks }\end{array}$ & $\begin{array}{c}\text { Crystal } \\
\text { diameter }(\mathrm{nm})\end{array}$ & $\begin{array}{c}\text { Error } \\
(\mathrm{nm})\end{array}$ \\
\hline$(111)$ & 14 & \pm 1 \\
\hline$(200)$ & 10 & \pm 1 \\
\hline$(220)$ & 8 & \pm 1 \\
\hline (311) & 10.2 & \pm 1 \\
\hline Average & 10.5 & \pm 1 \\
\hline \multicolumn{3}{|c|}{ Modified Scherrer } \\
\hline Diffraction & Crystal & Error \\
peaks & diameter (nm) & (nm) \\
\hline $\begin{array}{c}\text { (111) (200) } \\
\text { (220) (311) }\end{array}$ & 12 & \pm 1 \\
\hline
\end{tabular}

Fig. 6 a XRD pattern resulting from the characterization of a film produced from colloidal samples containing Au@Silica NPs. The samples were prepared using $E_{\text {pulse }}=50 \mathrm{~mJ}, \lambda=1064 \mathrm{~nm}$,

According to the 87-0597 and 01-1172 cards, those peaks belong to the FCC silver and gold structure and the calculated lattice parameter $\mathrm{a}=0.407 \mathrm{~nm}$ as well as the interplanar distances $d_{111}=0.235 \mathrm{~nm}, d_{200}=0.199 \mathrm{~nm}$, $d_{220}=0.144 \mathrm{~nm}$ and $d_{311}=0.122 \mathrm{~nm}$ agree well with the reported ones on the abovementioned cards. It is worth mentioning that under the growth conditions used for fabricating this sample, the substitution reaction (Eq. 1) holds and almost all silver was substituted for gold. Consequently, NPs formed are gold in composition.

Using these reflections, the Scherrer formula and a Voigt distribution for the diffracted radiation intensity, it was possible to estimate the crystallite size associated with each crystalline direction. Results of these calculations are presented in Fig. 6b. As the crystallite size can be limited by the metallic core size of NPs (metal@Silica), this result is an adequate estimation for the core diameter $\left(D_{\mathrm{NPs}}\right)$. Estimated crystallite size is different for each reflection suggesting that nanoparticles are not perfect spheres. Using the Scherrer and Scherrer modified method (Ahmad et al. 2012), the average crystallite diameter was estimated as $D_{\text {ave }}=(11 \pm 1) \mathrm{nm}$ and $D_{\text {ave }}=(12 \pm 1) \mathrm{nm}$, respectively.

Figure 7a and $\mathrm{b}$ shows TEM and HRTEM images of the synthesized NPs using $E_{\text {pulse }}=50 \mathrm{~mJ}, \lambda=1064 \mathrm{~nm}$, $f=20 \mathrm{~Hz}, t=20 \mathrm{~min}$ and $\left[0.25 \times 10^{-3}\right]$ of $\mathrm{AgNO}_{3}$ plus $\mathrm{HAuCl}_{4}$ (absorbance in Fig. 3a). Figure $7 \mathrm{~b}$ reveals that metallic NPs are coated with an amorphous shell of 3-5 nm thicknesses. This shell must be mainly silica, which is associated with the fast exothermic combustion reaction of $\mathrm{Si} \mathrm{NP}$ product of the ablation process in aqueous solution leading to their fragmentation and vigorous oxidation $\left(\mathrm{SiO}_{2}\right)$. HRTEM micrographs show that NP core is crystalline in nature. The insets in Fig. 7b $f=20 \mathrm{~Hz}, t=20 \mathrm{~min}$ and $\left[0.25 \times 10^{-3}\right]$ of $\mathrm{AgNO}_{3}$ plus $\mathrm{HAuCl}_{4}$. (Sample absorbance in Fig. 3a)

correspond to the Fourier transform of NP images, revealing the crystalline direction (111) of FCC structure. Interplanar distance obtained from the diffractogram $d_{111}=0.236 \mathrm{~nm}$ is in agreement with values obtained from XRD data.

TEM analysis images were processed to obtain information on the size and size distribution of the metal@Silica NPs. The size distribution study was carried out by manually outlining the nanoparticles (1500 NPs) from several micrographs of low and high resolution. Once digitized and saved in the proper format, the image was processed using the Gatan Digital Micrograph program. A Gaussian distribution was fitted to the histogram, obtaining an average size $D_{\text {ave }}=(14 \pm 2) \mathrm{nm}$ (Fig. 7c).

The size distribution of NPs extracted from this TEM analysis is slightly larger than that determined from XRD study. The latter must be associated with the apparently larger NP diameter observed in the TEM images due to the silica shell.

\section{Elemental distribution in the $\mathrm{Ag} / \mathrm{Au} @ \mathrm{SiO}_{2}$ alloy NPs}

To analyze the elemental composition, NPs were characterized by energy-dispersive X-ray spectroscopy, coupled to a transmission electron microscope in STEM mode. Figure 8 shows typical distribution maps of the following elements: $\mathrm{Au}, \mathrm{Ag}$, and $\mathrm{Si}$. The elemental maps are shown separately and compared with a TEM image (Fig. 8a). The synthesis parameters for the analyzed sample were: $E_{\text {Pulse }}=50 \mathrm{~mJ}, \lambda=1064 \mathrm{~nm}, f=20 \mathrm{~Hz}, t=20 \mathrm{~min}$, $\left[0.35 \times 10^{-3}\right]$ of $\mathrm{AgNO}_{3}$ plus $\mathrm{HAuCl}_{4}$. The absorption spectrum of this sample is shown in Fig. 4a. The electron probe (10 $\mathrm{nm}$ in diameter) of the TEM was focalized over 
(a)

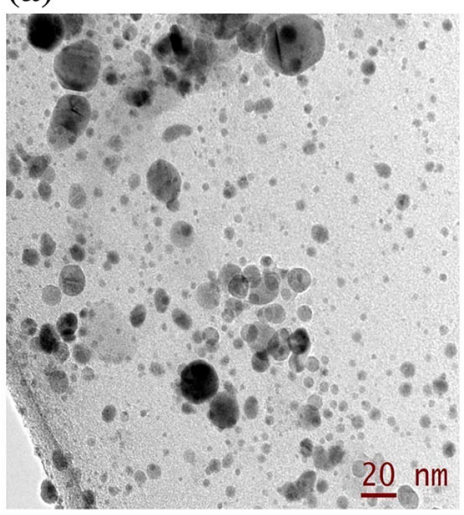

(b)

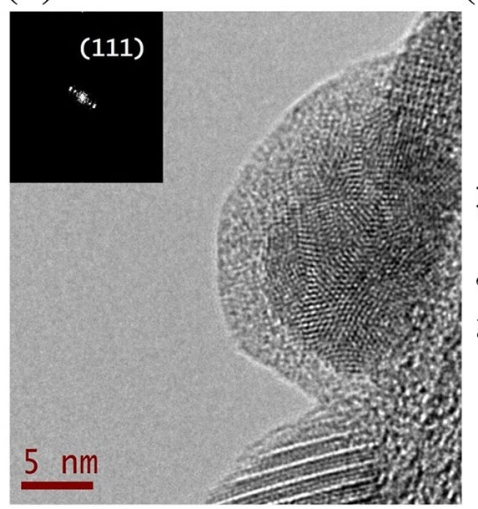

(c)

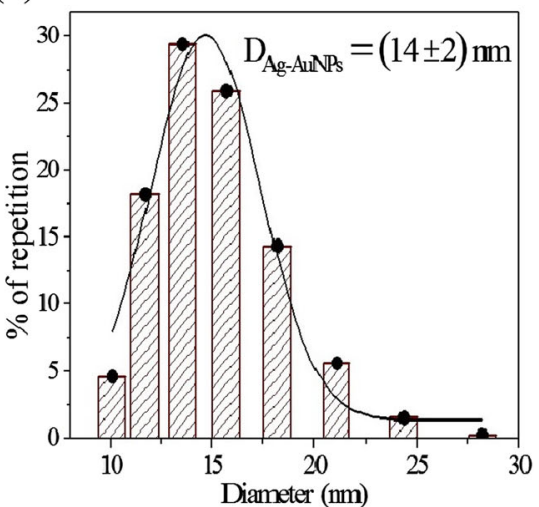

Fig. 7 a Transmission electron micrographs of $\mathrm{Ag} / \mathrm{Au} @ \mathrm{SiO}_{2}$ alloy nanoparticles. b HRTEM image of a silver/gold nanoparticle. The inset shows the Fourier transform of the NP image. c Size distribution of $\mathrm{Ag} / \mathrm{Au}$ alloy nanoparticles. Sample was synthesized using $E=50 \mathrm{~mJ} /$ pulse, $\lambda=1064 \mathrm{~nm}, t=20 \mathrm{~min}$, and $\left[0.25 \times 10^{-3}\right]$ of $\mathrm{AgNO}_{3}$ plus $\mathrm{HAuCl}_{4}\left(\mathrm{Ag}^{+} / \mathrm{Au}^{3+}=1\right)$
Fig. 8 a Transmission electron micrograph in STEM mode of an $\mathrm{Ag} / \mathrm{Au} @ \mathrm{SiO}_{2}$ alloy nanoparticle; b-d chemical mapping showing gold, silver and silicon, respectively. (Sample absorption spectrum in Fig. 4a)
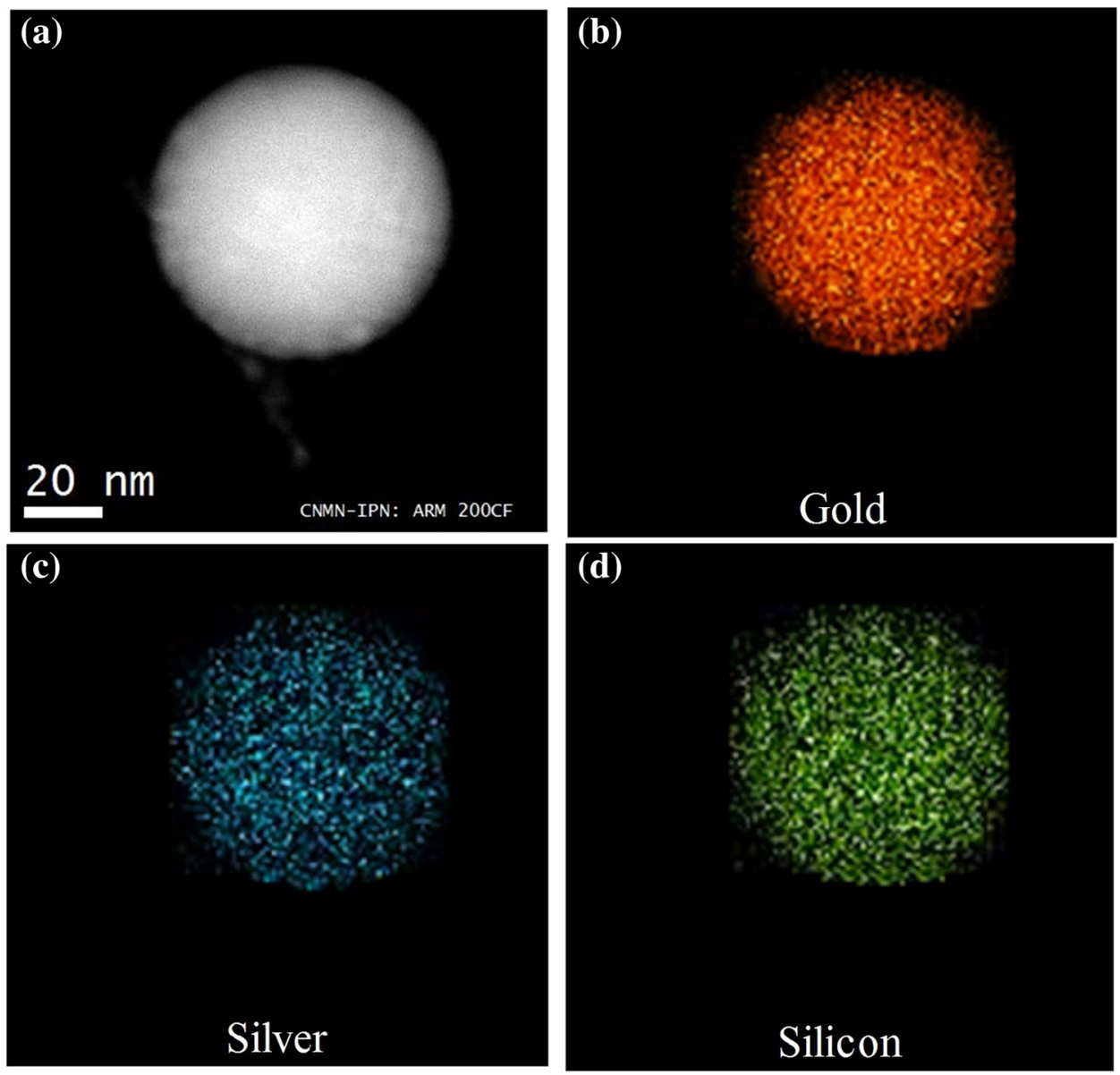

the NP surface and the EDS spectrum was acquired with a $\mathrm{Si}(\mathrm{Li}) \mathrm{X}$-ray detector.

Images reveal the intensity for gold is considerably higher than for both silver and silicon, suggesting the massive presence of gold in the nanoparticles. Maps for Ag and $\mathrm{Si}$ show that these elements are distributed sparsely.
Silicon must be distributed over the NP surface forming the amorphous silica shell observed by HRTEM. According to absorption spectra, only the gold LPSR is observed. Therefore, $\mathrm{AgCl}$ precipitated on the NP surface probably causes Ag's presence in the NP mapping. Notice that, owing to the substitution reaction (1), $\mathrm{AgCl}$ must be 
formed precipitating on the NP surface. Perhaps the high dielectric permittivity of $\mathrm{AgCl}$ precipitate on the NP surface (silica shell) may cause the great LSPR redshift $(\sim 550-562 \mathrm{~nm})$ observed in the Figs. 3a and 4a. Notice that an increase of the ablation time and pulse energy or a decrease of salt concentration provokes a minor redshift. This latter could be because the $\mathrm{AgCl}$ precipitate is distributed on a relatively larger silica surface.

\section{Conclusions}

$\mathrm{Ag} / \mathrm{Au}$ NPs coated with a silica shell were synthesized in three steps by combining the technique of assisted laser ablation and the redox mechanisms. The influence of synthesis parameters, laser pulse energy, ablation time, concentration of silver and gold salts and $\mathrm{Ag}^{+} / \mathrm{Au}^{3+}$ ratio on the optical and structural properties of the nanostructures was studied. The results show that NPs can be controlled by the laser pulse energy, ablation time and concentration of metallic salts. However, the laser pulse energy is the parameter that substantially increases NPs. The silica coating on the nanoparticles improves stability implying a long life span for these colloids. UV-Vis measurements in colloidal suspensions containing the Ag$\mathrm{Au} @ \mathrm{SiO}_{2} \mathrm{NPs}$ were conducted after several months of being synthesized and no changes in the absorbance spectra were detected, indicating a high colloidal stability of these suspensions. On the other hand, the silica coating provides inertness and innocuity character which entails possible use in biomedical applications. Additionally, the silica shell can protect the NP core from direct contact with, for example, luminescent molecules, enhancing the luminescence and avoiding luminescence quenching.

Acknowledgements J. R. González-Castillo and Eugenio RodríguezGonzález thank the Biophotonics Laboratory, from the Physics Institute "Gleb Wataghin", Campinas University, Brazil for the possibility to conduct experiments.

Author contributions J. R. González-Castillo conducted the experiments, processed and organized the information. E. RodríguezGonzález and E. Jiménez-Villar contributed to the design of experiments and manuscript writing. All authors contributed to the result analysis.

\section{Compliance with ethical standards}

Funding This work was supported by the Mexican founding agency Consejo Nacional de Ciencia y Tecnología (CONACyT) under project 183728. Authors also acknowledge the financial support from Instituto Politécnico Nacional under projects SIP20151327 and SIP20160171. E. Jiménez-Villar acknowledges FACEPE and CNPq (Grant 0116-1.06/13, APQ-0071-1.06/14), Brazil. E.J-V also acknowledges the FAPESP for financial supports (Grant PV-2017/ 05854-9).
Open Access This article is distributed under the terms of the Creative Commons Attribution 4.0 International License (http:// creativecommons.org/licenses/by/4.0/), which permits unrestricted use, distribution, and reproduction in any medium, provided you give appropriate credit to the original author(s) and the source, provide a link to the Creative Commons license, and indicate if changes were made.

\section{References}

Abderrafi K, Jiménez E, Ben T, Molina SI, Ibáñez R, Chirvony V (2012) Production of nanometer-size GaAs nanocrystals by nanosecond laser ablation in liquid. J Nanosci Nanotechnol 12:6774-6778

Ahmad M, Mohammad RF, Mohammad RM (2012) Modified Scherrer equation to estimate more accurately nano-crystallite size using XRD. Nano Sci Eng 2:154-160

Al-Azawi MA, Bidin N, Bououdina M, Mohammad SM (2016) Preparation of gold and gold-silver alloy nanoparticles for enhancement of plasmonic dye-sensitized solar cells performance. Sol Energy 126:93-104

Bankura KP, Maity D, Mollick MMR, Mondal D, Bhowmick B, Bain MK, Chakraborty A, Sarkar J, Acharya K, Chattopadhyay D (2012) Synthesis, characterization and antimicrobial activity of dextran stabilized silver nanoparticles in aqueous medium. Carbohyd Polym 89(4):1159-1165

Cobley CM, Skrabalak SE, Campbell DJ, Xia Y (2009) Shapecontrolled synthesis of silver nanoparticles for plasmonic and sensing applications. Plasmonics 4(2):171-179

Csapó E, Oszkó A, Varga E, Juhász Á, Buzás N, Körösi L, Majzik A, Dékány I (2012) Synthesis and characterization of Ag/Au alloy and core $(\mathrm{Ag})-$ shell( $\mathrm{Au})$ nanoparticles. Colloids Surf A 415:281-287

Ermakov VA, Jimenez-Villar E, Silva Filho JNCd, Yassitepe E, Mogili NVV, Iikawa F, de Sá GF, Cesar CL, Marques FC (2017) Size control of silver-core/silica-shell nanoparticles fabricated by laser-ablation-assisted chemical reduction. Langmuir 33(9):2257-2262

Fojtik A, Giersig M, Henglein A (1993) Formation of nanometer size silicon particles in a laser induced plasma in $\mathrm{SiH}_{4}$. Ber Bunsenges Phys Chem 97(11):1493-1496

Fuertes G, Sánchez-Munoz OL, Pedrueza E, Abderrafi K, Salgado J, Jiménez E (2011) Switchable bactericidal effects from novel silica-coated silver nanoparticles mediated by light irradiation. Langmuir 27:2826-2833

Garcia MA (2012) Surface plasmons in metallic nanoparticles: fundamentals and applications. J Phys D Appl Phys 45(38):389501

González-Castillo JR, Rodriguez E, Jimenez-Villar E, Rodríguez D, Salomon-García I, de Sá G, García-Fernández T, Almeida DB, Cesar CL, Johnes R, Ibarra J (2015) Synthesis of Ag@Silica nanoparticles by assisted laser ablation. Nanoscale Res Lett 10(1):1-9

Jiménez E, Arias JL, León B, Pérez-Amor M (2004) Electric discharge assisted pulsed laser deposition of hydroxylapatite. Thin Solid Films 453-454:422-426

Jiménez E, Abderrafi K, Martínez-Pastor J, Abargues R, Luís Valdés J, Ibáñez R (2008) A novel method of nanocrystal fabrication based on laser ablation in liquid environment. Superlattices Microstruct 43(5-6):487-493

Jiménez E, Abderrafi K, Abargues R, Valdés JL, Martínez-Pastor JP (2010) Laser-ablation-induced synthesis of $\mathrm{SiO}_{2}$-capped noble metal nanoparticles in a single step. Langmuir 26:7458-7463 
Jimenez-Villar E, Mestre V, Oliveira PC, Sá GF (2013) Novel coreshell $\left(\mathrm{TiO}_{2} @\right.$ Silica) nanoparticles for scattering medium in a random laser: higher efficiency, lower laser threshold and lower photodegradation. Nanoscale 5:12512-12517

Jimenez-Villar E, Mestre V, Oliveira PC, Faustino WM, Silva D, Sá GF (2014) $\mathrm{TiO}_{2} @$ Silica nanoparticles in a random laser: strong relationship of silica shell thickness on scattering medium properties and random laser performance. Appl Phys Lett 104:081909

Jimenez-Villar E et al (2016) Anderson localization of light in a colloidal suspension $\quad\left(\mathrm{TiO}_{2} @\right.$ Silica). Nanoscale 8(21):10938-10946

Jimenez-Villar E et al (2017) Random lasing at localization transition in a colloidal suspension $\left(\mathrm{TiO}_{2} @\right.$ Silica $)$ ACS Omega 2:2415-2421

Kellermann G, Rodriguez E, Jimenez E, Cesar CL, Barbosa LC, Craievich AF (2010) Structure of PbTe $\left(\mathrm{SiO}_{2}\right) / \mathrm{SiO}_{2}$ multilayers deposited on Si (111). J Appl Crystallogr 43:385-393

Kumar V, Yadav SK (2009) Plant-mediated synthesis of silver and gold nanoparticles and their applications. J Chem Technol Biotechnol 84(2):151-157

Liao X, Chen Y, Qin M, Chen Y, Yang L, Zhang H, Tian Y (2013) $\mathrm{Au}-\mathrm{Ag}-\mathrm{Au}$ double shell nanoparticles-based localized surface plasmon resonance and surface-enhanced Raman scattering biosensor for sensitive detection of 2-mercapto-1-methylimidazole. Talanta 117:203-208

Liu X, Cheng H, Cui P (2014) Catalysis by silver nanoparticles/porous silicon for the reduction of nitroaromatics in the presence of sodium borohydride. Appl Surf Sci 292:695-701

McCarthy MC, Gauss J (2016) Exotic $\mathrm{SiO}_{2} \mathrm{H}_{2}$ isomers: theory and experiment working in harmony. $\mathrm{J}$ Phys Chem Lett 7(10):1895-1900

Nasrabadi HT, Abbasi E, Davaran S, Kouhi M, Akbarzadeh A (2016) Bimetallic nanoparticles: preparation, properties, and biomedical applications. Artif Cells Nanomed Biotechnol 44(1):376-380

Olea-Mejía O, Fernández-Mondragón M, Rodríguez-de la Concha G, Camacho-López M (2015) SERS-active Ag, $\mathrm{Au}$ and Ag-Au alloy nanoparticles obtained by laser ablation in liquids for sensing methylene blue. Appl Surf Sci 348:66-70

Popovici N, Jimenez E, da Silva RC, Branford WR, Cohen LF, Conde $\mathrm{O}$ (2006) Optical and magnetic properties of co-doped $\mathrm{TiO}_{2}$ thin films grown by pulsed laser deposition. J NonCryst Solids 352:1486-1489

Prabhu S, Poulose EK (2012) Silver nanoparticles: mechanism of antimicrobial action, synthesis, medical applications, and toxicity effects. Int Nano Lett 2(1):1-10

Pyatenko A, Shimokawa K, Yamaguchi M, Nishimura O, Suzuki M (2004) Synthesis of silver nanoparticles by laser ablation in pure water. Appl Phys A 79:803-806

Pyatenko A, Yamaguchi M, Suzuki M (2007) Synthesis of spherical silver nanoparticles with controllable sizes in aqueous solutions. J Phys Chem C 111:7910-7917

Qingbo Z, Lee JY, Yang J, Boothroyd C, Zhang J (2007) Size and composition tunable $\mathrm{Ag}-\mathrm{Au}$ alloy nanoparticles by replacement reactions. Nanotechnology 18(24):245605

Rodriguez E, Jimenez E, Padilha L, Neves A, Jacob G, Cesar C (2005) $\mathrm{SiO}_{2} / \mathrm{PbTe}$ quantum-dot multilayer production and characterization. Appl Phys Lett 86:113117

Rodriguez E, Kellermann G, Craievich AF, Jimenez E, César C, Barbosa L (2008) All-optical switching device for infrared based on PbTe quantum dots. Superlattice Microstruct 43:626-634

Sánchez-Muñoz OL, Salgado J, Martínez-Pastor J, Jiménez-Villar E (2012) Synthesis and physical stability of novel Au-Ag@ $\mathrm{SiO}_{2}$ alloy nanoparticles. Nanosci Nanotechnol 2(1):1-7

Shiomi S, Kawamori M, Yagi S, Matsubara E (2015) One-pot synthesis of silica-coated copper nanoparticles with high chemical and thermal stability. J Colloid Interface Sci 460:47-54

Zhang J, Malicka J, Gryczynski I, Lakowicz JR (2005) Surfaceenhanced fluorescence of fluorescein-labeled oligonucleotides capped on silver nanoparticles. J Phys Chem B 109(16):7643-7648

Zhang J, Chaker M, Ma D (2017) Pulsed laser ablation based synthesis of colloidal metal nanoparticles for catalytic applications. J Colloid Interface Sci 489:138-149

\section{Publisher's Note}

Springer Nature remains neutral with regard to jurisdictional claims in published maps and institutional affiliations. 